\title{
The Role of Positive Emotions in Experiential Decisions
}

\author{
ROBERT J. KWORTNIK, JR.* \\ and \\ WILLIAM T. ROSS, JR.
}

\begin{abstract}
* Robert J. Kwortnik, Jr. is an assistant professor of marketing at the Cornell University School of Hotel Administration, 545 Statler Hall, Ithaca, NY, 14850 (rjk34@cornell.edu). William T. Ross, Jr. is a professor of marketing at the Pennsylvania State University Smeal College of Business, 707-H Business Administration Building, University Park, PA, 16802

(wtr2@psu.edu). Correspondence: Robert J. Kwortnik. This research is based on the first author's dissertation at Temple University (co-chaired by William T. Ross, Jr. and Terence A. Oliva). The authors thank Richard Celsi, Jennifer Chang Coupland, Michael D. Johnson, Mellie Pullman, Stephani Robson, Stewart Shapiro, and three anonymous reviewers for their insightful comments on drafts of this paper, and especially Hope Jensen Schau for her invaluable contributions.
\end{abstract}

Published in the International Journal of Research in Marketing (2007), 24 (December), pp. 324-335. Winner of an Emerald Management Reviews Citation of Excellence award. 


\title{
The Role of Positive Emotions in Experiential Decisions
}

\begin{abstract}
This research examines how consumers experience decision making for experiential products such as vacations. We combine data from 1) ethnographic interviews, 2) online community discussion forums, and 3) an introspective vacation-planning task to explore the experience of emotion in the decision process and to develop a new model of decision making that extends extant decision theories. We find that consumers experience a variety of positive emotions as they plan vacations, from facilitative feelings that guide the plan to fantasy feelings consumed for pleasure. Positive emotions are most evident in reaction to imagery and when the consumer's self identity is salient, and often precede more analytic information processing. Overall, this research offers a richer understanding of the emotional nature of consumer decision making for experiential products and services.
\end{abstract}

Key words: emotion, imagery, self-identity, consumer decision making, experiential products 


\section{INTRODUCTION}

Consumers do more than cogitate to solve consumption problems; they also desire (Belk, Ger, \& Askegaard, 2003), feel (Pham, 1998), imagine (Shiv \& Huber, 2000), and construct self identity (Ahuvia, 2005). However, traditional choice models and reason-based decision strategies (c.f., Bettman, Johnson, \& Payne, 1991) do not fully capture the factors that influence consumer decisions in contexts that are more experiential in nature. We strive to extend choice theory by listening for emotion, particularly positive emotion, in consumers' decision narratives. Our research objective is to better understand how, when, and why consumers experience positive emotions during the decision making process, and in what way these emotions influence their choices.

The call for research on emotion and consumer experience is not new (Holbrook \& Hirschman, 1982). Scholars have shown that consumption often results in affect, such as anger or satisfaction, and that emotional reactions to advertising are often homogenous, reliable, and predictive of attitudes and judgments (Pham, Cohen, \& Pracejus, 2001). Typically, though, when affect has been studied as an input to decision making, it has been as a mood unrelated to the decision, not as an emotion elicited by the target and/or task. This distinction is important because emotions and moods can influence decisions, yet each provides different information to decision makers (Cohen \& Areni, 1991; Isen, 1993; Schwarz \& Clore, 1996). Some studies have shown that consumers monitor their feelings when making decisions (Pham, 1998; Shiv \& Fedorikhin, 1999; Yeung \& Wyer, 2004). However, much remains unknown about emotion and decision making, in particular by what mechanism feelings inform judgments, i.e., through mere affect transfer or through perceiving feelings as valid sources of information in their own right (Pham, 2004).

Proponents of the experiential view of consumer behavior have argued for extending information-processing theories by integrating feelings into extant decision models (Holbrook \& Hirschman, 1982; Peterson, Hoyer, \& Wilson, 1986). We strive for this integration by using qualitative research methods to explore how emotions are engaged in the experiential-decision context, how they are lived and revealed by the consumer, and how they are consumed, both as information and as inputs to hedonic experience. Our main contribution is a phenomenological view of experiential decisions and the nature of emotion in the process.

We begin by briefly reviewing the consumer decision-making literature, though we refrain from developing a priori theory and instead enable our theoretical understanding to emerge from the data. We then describe our methodology, present an emergent model, and report findings grounded in consumers' experiences that extend extant theory. We close with a discussion of key themes and implications for marketing theory and practice.

\section{EMOTION IN CONSUMER DECISION RESEARCH}

Consumer-choice theories have long relegated emotion to a secondary or subsequent role. Studies of emotion and decision making have largely focused on negative emotions (e.g., Luce, 1998), though the more common reactions to anticipation of consumption are joy, happiness, excitement, and similar expressions of positive feelings (Derbaix \& Pham, 1991; Richins, 1997). The notion that making a choice can be enjoyable runs counter to the behavioral-decision-theory view that consumers perceive decision making as unpleasant and effortful (Bettman et al., 1991). Studies of automatic, visceral affective reactions suggest that a desire for positive emotional experiences can motivate choice behavior (Shiv \& Fedorikhin, 1999). Research looking at 
controlled processing of affective information also found that anticipation of satisfaction (Shiv \& Huber, 2000) and emotional expectations (Neelamegham \& Jain, 1999) impact choice. Pham (1998) reported that consumers use affect as information when feelings are viewed as representative of a target under consideration and relevant to the judgment task. Yeung and Wyer (2004) showed that consumers' appraisals of product images produced affect-based impressions that influenced later evaluations, regardless of judgmental criteria normally used. Researchers have also described a motivational role for intense emotions (e.g., thrill, joy, and flow) in decisions to participate in extraordinary experiences such as river rafting (Arnould \& Price, 1993). Thus, the pleasure of consumption can begin before the act of consuming; that is, the consumer has fun anticipating consumption and in the experience of choosing, and rationalizing during decision making sometimes takes the fun out of it.

There has been considerable debate about the emotional system and the timing of emotions. Zajonc (1980) argued that affective reactions to stimuli often precede extensive cognitive processing. This affect-primacy view is consistent with evolutionary psychology and the theory that emotions serve to ensure a readiness to respond, such as with approach/avoidance behaviors or by motivating and guiding further information processing. Research from neurophysiology (Damaiso, 1994) and consumer behavior (see Pham, 2004) supports the view that affect can encourage "thought mobilization" by directing attention to information that confirms initial feelings. In contrast, appraisal theorists argue that emotions are a response to meaning that results from the cognitive evaluation of something relative to desired end states, goals, or beliefs (e.g., Bagozzi, Gopinath, \& Nyer, 1999; Lazarus, 1991). Extensions of this theory, such as Bagozzi, Baumgartner, and Pieter's (1998) model of goal-directed anticipatory emotions, similarly posit that emotions serve as a feedback mechanism for the behavioral system, with progress toward a goal eliciting positive emotions.

Traditional decision research assumes that consumer goals conform to a utility construct, which Hirschman and Holbrook (1982, p. 94) contended is "inappropriate for products whose selection and use are based upon satisfying emotional wants, rather than fulfilling utilitarian functions." This overlooks a rich set of goals, such as consumption for "phatic communion" among group members (Celsi, Rose, \& Leigh, 1993), for "self-illusory imaginative hedonism” (Campbell, 1987) or for self-extension (Belk, 1988). Likewise, studies of tourism reveal an array of goals: achievement, fun, bonding, relaxation, escape, nostalgia, novelty, and otherness (Otto \& Ritchie, 1996; Pearce \& Lee, 2005). Though pursuit of pleasure has face validity as a goal of hedonic consumption, research suggests that a pleasure motive is less important as higher-order goals related to self-identity become salient (Arnould \& Price, 1993; Celsi et al., 1993). As Averill and More $(1993,620)$ asked, "Do people engage in activities in order to be happy, or are people happy because they engage in activities that successfully lead to goals other than happiness (fame, fortune, or whatever)?” Scholars generally agree that a goal is an end state toward which behavior is directed, whereas a motivation is an inner drive that moves a person to goal-directed action (Bagozzi \& Dholakia, 1999). Though goals such as happiness and pleasure are defined as positive emotions (Lazarus, 1991), emotions are more often cast as motivations that influence goal-directed behavior (Bagozzi \& Dholakia, 1999). Research is needed to unravel the relationship between decision goals and emotions.

Scholars have offered conceptual arguments for the role of emotion in consumer decision making (Campbell, 1987; Cohen \& Areni, 1991; Holbrook \& Hirschman, 1982; Peterson, Hoyer, \& Wilson, 1986); however, limited empirical research exists that gives form to these ideas (for exceptions, see Pham, 1998; Tsai, 2005; Yeung \& Wyer, 2004). Researchers have generally inferred the presence of decision emotions from consumers' revealed preferences (Pham, 2004). The study that follows is designed to advance knowledge by focusing on the phenomenology of 
decision emotion, including its form, timing, influence, and lived experience, to construct a richer view of consumer choice that highlights emotional experience.

\section{METHODOLOGY}

\section{Research Context: Experiential Products}

Products in choice research tend to lack experiential dimensions (Dhar \& Wertenbroch, 2000; Shiv \& Fedorikhin 1999), despite criticism that this omits important types of consumption, such as entertainment and leisure (Holbrook \& Hirschman, 1982). It is not surprising, then, that researchers have found little role for positive emotion in decision making. Many products can be hedonic, but some are more emotionally involving (Campbell, 1987). For example, Van Boven and Gilovich (2003) found that experiential purchases (e.g., dining and travel) made people happier than material possessions. We conceptualize an experiential product as fusing tangible (sensory) and intangible (symbolic) attributes and co-produced by consumer and marketer to create an event that is pleasurable, meaningful, and memorable. The experience is the product in a holistic sense. An experiential product is sought for subjective, psychological reasons“fantasies, feelings, and fun” (Holbrook \& Hirschman, 1982), as opposed to objective, instrumental benefits (Van Boven \& Gilovich, 2003). Exploring decisions for experiential products should reveal the emotional nature of the process more so than for instrumental products. We focus on vacations, a broad subtype within the category of experiential products, which offer a rich source of data because people like to share their vacation stories and plans.

\section{Overview of the Discovery-Oriented Research Method and Data Sources}

We used a multi-method research approach to triangulate on the nature of emotional experience during consumer decision making for experiential products. Our main methodology was grounded theory (Strauss \& Corbin, 1998), which is designed to build an understanding of phenomena through an iterative process of data collection, analysis, and interpretation.

Data were collected in sequence from three sources: depth interviews, online discussion boards and chat rooms, and a vacation-planning task. Each subsequent data set was selected to offer different perspectives and hopefully convergent interpretations. The interviews provided insights into consumers' personal goals and experiences, though the data was inclined toward memories of the decision process, which were often shaded by the more vivid recall of the consumption experience itself. The use of online forums partially addressed the interviews' postdecision orientation and expanded the focus from planning to post-event discussion. Though we were able to capture consumers' live decision experiences, these data rarely spanned the full decision process, but rather captured snapshots of decision moments. We were also limited by our role as observers and the anonymity of the forums, which precluded the ability to probe for personal decision influences. Thus, as patterns emerged from the analysis of the interview and online data, we sought data to corroborate our provisional interpretations. Specifically, we asked student participants to document the planning of a hypothetical vacation, from concept to choice. Although the task possessed a degree of artificiality due to researcher-imposed instructions, it more precisely chronicled the decision process. In sum, each data set had advantages that together permitted a more complete view of the nature of the experiential-decision process. 


\section{Data Collection Processes and Analytic Procedures}

Personal Semi-Structured In-Depth Interviews. We conducted 32 in-depth interviews with 36 informants (four married couples were interviewed together; see the appendix). Informants were known to the researchers to encourage emotional openness (Price, Arnould, \& Curasi, 2000). Because informants might try to mask their emotions to present the image of being a logical decision maker, comfort was expected to minimize impression management. Moreover, knowledge of the informant's background revealed a person-product-action context (Price et al., 2000) which proved valuable for data analysis and for shaping the interview itself.

Interviews lasted between 30 and 90 minutes and were audio recorded and later transcribed to roughly 600 pages of text. Sessions began with "idle chatter" (McCracken, 1988), after which informants were read an ethics protocol and asked for demographic data. They also participated in a projective exercise, a verbal word association and a sentence completion task, designed to elicit perceptions of themselves. The responses offered insights into the informants' self-identities that supplemented the researchers’ prior knowledge of the individuals.

We first asked informants to describe recent vacations, including the shopping process. The intended perspective was grounded in the informant's words and point of view (McCracken, 1988; Mick \& Buhl, 1992). To help understand why a choice was made, in addition to how, we also probed directly for what may have shaped the decision process. Most informants provided clear, ready reasons for why they made the plans they did. Additional insights were gleaned by comparing an informant's interpretations of "Why this decision?" to the researcher's interpretation of informants' goals and motives.

We began analysis by determining self-identity themes culled from the biographical data, responses to the projective exercise, and the interview text. Analysis proceeded by coding the data for meaning. In some cases, in vivo codes (Strauss \& Corbin, 1998) were given by informants as they interpreted their experiences, though in most cases coding involved textual analysis and the use of new labels or ones taken from the literature. With the inclusion of new interviews (and, later, the online data), the analytic strategy shifted to comparative analysis for patterns and themes that informed our interpretations (Strauss \&, Corbin 1998). ${ }^{1}$

Online Vacation Discussions. Data collected from online vacation forums included unknown consumers' voices mined from 35 threads and archived chat sessions regarding lodging, sightseeing, activities, and events, across five randomly selected destinations (Bermuda, Hawaii, Jamaica, South Africa, and Switzerland). Assuming that each screen name is a unique person, we observed 234 consumers in public, naturally-occurring discussion of their vacation planning. These consumers were identified only by screen name and their signature or site profiles.

Vacation Task and Follow-up Survey. To better ensure that the obtained data focused on the decision process for vacations, we asked 57 university students (for course credit) to plan a hypothetical vacation using $\$ 3,000$ in prize money. They were asked to document their plans and rationales, and their thoughts and feelings as they were exposed to stimuli that influenced their decision. We emailed them a survey six to nine months after task completion (78\% response rate) and found that $61 \%$ of the respondents implemented their planned vacation, and another $27 \%$ intended to do so in the near future.

Research assistants who were naïve to the study's focus performed the majority of the

\footnotetext{
${ }^{1}$ To help ensure that interpretations reflected the voices and experiences of the interview informants, we used member checks by providing drafts of our findings for informant inspection and feedback. In this way, informants become collaborators in the research process, and the interpretive outcome more closely represents their experience as they perceive it to be (Lincoln \& Guba, 1985).
} 
analysis of the vacation-task data. We introduced two research assistants to concepts from the grounded-theory analysis to aid in performing independent content analyses of the vacation tasks. For each case, they identified the presence/absence of decision elements: consumption goals, imagery, emotional responses, attribute analysis, and others. They also determined how the decision unfolded by mapping the order of events in the process using the identified decision elements. The coders agreed on $80 \%$ of the decision-element present/absent judgments; disagreements were resolved by a third coder who broke all ties. The reliability of the decisionsequence analysis was determined by correlating the ranking of each decision element for each case across the two coders (relaxing the assumption of independence), producing a Pearson $r$ of $0.66(\mathrm{~N}=212)$. Discrepancies in the order rankings were reconciled by a third coder.

\section{EMOTIONS AND EXPERIENTIAL DECISIONS}

\section{Overview of Findings and the Experiential-Decision Model}

Analysis of data from interview informants, online posters, and vacation-task participants reveal that vacations are a repository for a web of goals, meanings, and feelings. Vacations inspired by self-relevant themes are likely to involve imagery and emotion during the decision process. The closer to the self the vacation experience is, the more emotional the decision becomes, though the nature and influence of emotion differs across decision makers and moments in the process. For many consumers, the vacation idea and product stimuli are imagined and compared with self-relevant goals to determine whether it feels right. Salient emotional responses are appraised for informational value and can directly affect preferences, while more subtle emotional responses can indirectly affect preferences by shading and/or guiding subsequent analytic processing to determine which option fits right (see figure 1). We name this process the Experiential-Decision Model to capture both the decision context and the idea that the process itself is an experience.

\section{[Insert figure 1 about here]}

Analysis of the vacation tasks supports the model. Coders determined the presence or absence of the decision elements featured as boxes in the model, and numbered the elements in each task based on the temporal sequence in the process. These sequence scores were averaged across the tasks to produce the following aggregate order (see table 1): consumption goal processing $(\mathrm{M}=1.4)$, imagery $(\mathrm{M}=3.0)$, emotional response $(\mathrm{M}=3.9)$, attribute analysis $(\mathrm{M}=$ 4.6), emotion appraisal $(M=4.9)$, choice $(M=5.5)$ and preference $(M=5.7){ }^{2}$ Emotional response was nearly twice as likely to occur earlier in the decision process then fact-based attribute analysis. While the model suggests a linear structure to experiential decisions, the data often revealed a complex process with all manner of sequences and feedback effects, as well as mini-decisions within a larger decision process. Emotions were sometimes evident early in the process, sometimes at the end, and sometimes seemingly not at all. Thus, the ExperientialDecision Model represents a generalized depiction of a behavioral process with numerous variations and nuances. It is these phenomenological off-roads that represent the main contribution of this research. We next trace the experiential-decision process and illuminate our

\footnotetext{
${ }^{2}$ Although choice is logically the final part of the process, in one out of five tasks, the coders determined that choice came first or second; i.e., participants had predetermined much of the vacation experience (e.g., visiting Disneyland), so much of the decision process focused on completing the vacation package or affirming the choice.
} 
findings by placing them back in the context of the lived experience from which they emerged.

\section{[Insert table 1 about here]}

\section{Decision Framing and the Significance of Self}

Vacations are important in consumers' lives: some mark significant life moments, such as getting married, completing a degree, or sending a child to college. Others serve a reparative function, such as relaxation, escape, or a change of scenery. Mia explains: "For my marriage, it's important that we get away from our jobs. It's an opportunity for us to have no demands on our time and to be with each other." Likewise, Bryce describes vacations as "an opportunity to refill my tank and refresh and re-energize ... [to see] different places and different people ... [to] give me different points of view so that I can feel better about myself-maybe, ultimately.” Though people want to have fun on a vacation, fun is rarely the main goal of the experience. Informants tend to characterize others as fun seekers, but describe themselves as searching for more. Ana tentatively (and symbolically) explains why vacations for her are learning experiences and not just fun:

A lot of people when they go on a trip ... they go for different reasons.... They go to be with [other] people and, you know, to have fun with people. Perhaps because money wasn't very plentiful as I grew up.... [It's] very difficult for me to go to a buffet that I've paid for and not eat everything on that buffet. A trip is almost like that.

Significance of Self. Consumers often discussed self-relevant vacation experiences. For example, Regan, a schoolteacher, describes her tour of Italy as an "educational experience," because she explored a different culture, felt "a part of history" that she had read about, and learned about herself by being in unfamiliar surroundings. For Maria, newly married and in a new home, her ski vacation symbolizes an emerging self: "I like the challenge ... maybe it's just who I grew up with, having brothers, just following them in skiing or in their sports, just trying to keep up with them.” Similarly, TRUdeel, a poster to an online Jamaican-travel forum, writes, “I need to plan 'da trip' my way. I'm thru wit [with] college and unemployed: Ain't it a shame? It's about da [the] long run. what type of runner am I??... I need a lil' [little] reggae time and a place to revise.” TRUdeel frames his vacation entirely around self-discovery.

Interview informants often described vacations as reflective of who they are. To explore the connection between the self and vacation decisions, informants' plans were analyzed as identity projects influenced by self themes, the self-identity issues or "existential concerns" (Mick \& Buhl, 1992) that often guide behavior. For example, Toby, a security manager, admits to being money conscious. He gives prices for past vacations, noting which ones were "cheap." A self theme for Toby is financial striving, which directs several identity projects, including buying a house in a "working class" neighborhood, and a home improvement project that he performed himself. This theme also guides Toby’s experiential self, which we conceptualize as a possible self (Markus and Nurius 1986) that emerges in a specific context, here, the vacationexperience context. For Toby, the goal of a vacation is to relax, which he would be fine doing at home. But since he must travel to please his wife, not worrying about money helps him to relax:

An all-inclusive is important. After doing that, I'll never do anything else. It's the way to go. No money, no tips, no credit cards to worry about. Nothing to worry about really.

You go out with the bathing suit you have on and they give you a bracelet and you don't have to worry about a damn thing. Ah yea! I love that.

For Toby, the all-inclusive resort is a vehicle for satisfying his vacation self. It offers passage: when he enters the resort, he puts away the worrisome accoutrements, the wallet and credit cards, 
of his financial-striving self and instead puts on the resort bracelet and a new self-identity.

The relationship between experiential product choice and self-identity antecedents is represented in the model as waves projected to/from the self and consumption goals, which reflect the meanings sought by consumers via the vacation experience. For example, Lea's selfidentity is rooted in her roles as a wife and mother of three children aged 16, 11, and 8. Lea's self themes involve such projects as unifying her family and giving her children the types of memorable experiences (e.g., a river-rafting and dude ranch vacation) that were absent from her childhood. Her goals reflect the desire for family time, sharing, and memories:

I'm big on creating memories. Because I didn't grow up going on trips, I'd think about what it would feel like to [vacation] like this, so it is a big deal to me to create memories for the kids. I knew it was going to be a good experience to all be together. It just seemed like a year when we weren't all together so I was really looking forward to that, too. So I was thinking it was three weeks of solid time together... and hoping it would work! For Lea, self-identity issues and the looming departure of her first child for college activated goals related to family bonding and creating experiences for her children before they grow up:

For some of these trips with the kids, it's a sudden moment of, my gosh, they're getting older. It's almost this urgency. We have to get these experiences in before we are no longer able to as a family. Time, you know, nobody feels like they have enough time. And I guess when we're frenzied and feeling totally overbooked with everything, kids' activities, work, that tends to be when we make a decision to take a trip like this.

Consumption Goals. Consumers bring myriad consumption goals to the experientialdecision process. Consistent with tourism research (see Pearce and Lee 2005), we found goals such as making memories, learning, discovery, sharing, escape, romance, relaxation, and attaining a good value. Though pursuit of hedonic benefits is a key aspect of vacations, consumers are not mindless in this pursuit. A theme in our data is the desire to "make the most of the experience," which means making the most of the self, where the vacation self is a core or true self (Belk, 1988). Lea illustrates this idea in her description of "vacation mode":

It's being more like a kid ... relaxed ... you know? Normally there's so much family

obligation at home, [but] ... we're both completely ourselves when we're away, and it's important for the kids to see two relaxed parents, because they've seen such intensity. Striving for the vacation self is what makes vacations fun. We find that positive emotion is most evident and relevant when the self is salient in the decision process, consistent with the theory that positive emotion is a self-monitoring mechanism that provides information about the selfrelevant benefits of behavior (e.g., Bagozzi et al., 1998; Carver \& Scheier, 1990).

Some vacations are motivated more by social, business, or market opportunities than by self-identity themes. For example, Maria noted that she tries to "tag along" with her husband on business trips to "make the most of the opportunity." A vacation that Jack took with his wife was prompted by a discount airfare and hotel loyalty points, not by some special event or need. In these cases, there is little decision emotion involved. The difference between such experiences and self-motivated decisions is captured by Lea in her comparison of two vacations: a cruise that was an add-on to one of her husband's business trips, and the river-rafting adventure:

This Alaskan cruise that we're going on, there's not much planning ... there are things available to you and you sign up ... so it's not as much of an individual planned vacation as the one we took last year. That one was more what we felt like doing. (italics added)

\section{Influence of Imagery}


One theme that pervades the data is the multifaceted role played by imagery. Consumers react to images of all types, from pictures and/or verbal images found in product promotions to imagined consumption and fantasy (Belk et al., 2003; Campbell, 1987). Vacation-task coders determined that $90 \%$ of the tasks involved imagery, most often piecemeal processing of pictures of destinations, lodging, activities, etc., although in $70 \%$ of the tasks, imagery was also holistic, akin to a first impression, or what Lea refers to as "the big picture." For instance, PlanB posts on a Hawaiian forum: "Hawaii IS paradise. It is THE place I want to be when life gets complicated — when I fight with my girl, when my boss jacks me-I picture myself long goneto Maui." Will also offers a holistic image of Hawaii: "I was looking forward to the tropical atmosphere, the clear water and just being in this tropical place."

Imagery was four times more likely to be processed before fact-based product attribute analysis, and emotion often followed; hence the positioning of imagery in the ExperientialDecision Model. The nature and goals of experiential consumption focuses attention on images in the environment and daydreams that often engender somatic and emotional experiences which both facilitate meaning making and are often consumed for their own enjoyment (Belk et al., 2003; Campbell, 1987). For example, TakeHerAway posts to the Jamaica forum:

My girl says we need to get away. I reluctantly agree. I start stressing over my wallet.... I see this slide show link on Dizzy's signature file.... WOW, the images blow me awaygorgeous, breath stealing. I'm looking at the beach, the sunset, and my mind jumps to another gorgeous thought-her body in that stringy suit I bought her last summer. Oh my! Damn, cut me a slice of that. Next thing I know, I'm booking the flight....

TakeHerAway is inspired by another poster's vacation pictures. He imagines his girlfriend in her stringy suit and then amorous feelings motivate him to book right then. Like TakeHerAway, L8R Loser reacts to imagery on an online message board for Bermuda:

I am online looking up financials for a competing firm for a report that has been on my desk for eons. Bored I decide to vacation online-just check out some sites on Bermuda. I see the images. I see the threads. I jack the report.... I'm soaring with excitement. Illicit stolen corporate time-the thrill is the vacation and the cheating on my job with thoughts of recreation. My heart is racing. I'm warm like I jogged three blocks-not a full on run, but misty. Bermuda here I come.

L8R Loser offers an imagery- and emotion-fueled decision, with emotion manifested in words like "excitement" and in somatic reactions like "heart racing” and "misty." Both L8R Loser and TakeHerAway are "artists of the imagination” for whom vacation planning is self-illusory imaginative hedonism (Campbell, 1987). Their emotional responses represent how consequences associated with the plan reduce the discrepancy between actual and desired states of being.

The following vacation-task text is similarly illustrative of the interplay of imagery and emotion in vacation decisions:

Monday nights I watch the casino drama, Las Vegas. I think about how exciting it would be to join in the crazy nightlife, visit the restaurants, see the shows, and gamble. The title song gets me pumped up. The stream of images of the city ... makes me feel a strong yearning to be part of it all. On this particular Monday, with vacation in mind, I began to feel that Vegas was the perfect mix of excitement, adventure, and romance that I was looking for. When I began to rationally think it through, it seemed like a plausible locale since they have all-inclusive packages that would cut down on expenses.

This narrative shows the participant reacting emotionally to the television show. The interaction of imagery and emotion leads to the feeling that Vegas is what s/he is looking for. Only after an emotional response does she "rationally think it through" in an unemotional, calculated way. 


\section{Positive Decision Emotion: How Does It Feel?}

Many of our research participants spoke of general feelings of excitement while vacation planning. For example, Mia enjoys doing online vacation research for “anticipation”: "I get to go on vacation for months before I'm on vacation.” Mark and his girlfriend Paula also enjoy vicarious vacationing: "We spent time researching the places we were going because it was fun. The planning was a bit like a mini-vacation before the vacation started.” We find that vacation decisions, though often involving a deliberate and reasoned process, are also fun because deciding is an experience itself, and there is pleasure in the planning. This insight highlights a phenomenon that has received little attention from consumer researchers: the effects of positive task-induced affect on the decision process (c.f., Garg, Inman \& Mittal, 2005; Luce, 1998).

Despite such recollections of general feelings of excitement, anticipation, and pleasure while vacation planning, unaided recall of specific decision emotions by interview informants was limited, a finding consistent with research which suggests that people can be "unreliable historians of their past emotions" (Pham, 2004) and that literal language is often inadequate for accessing emotions (Zaltman, 1997). Recalled emotion during vacation planning was present, but often cloaked in symbolism. For example, in retelling what he seeks from vacations, Jack equates sharing discoveries with his wife, such as a mountain view, as being "a little bit like Christmas when you're a kid ... like opening a present.” Tim describes planning his ski vacations as "refreshing mentally" and an "attitude adjustment." He imagines "white cap peaks and dry, crisp air, and the strong sunshine ... that sort of feeling." Staci, who labels herself "passionate," confides that an annual trip with her girlfriends is emotional from the planning to the doing. Beyond "fun," she did not recall specific emotions her vacation plans triggered, though she references emotional markers from past vacations-a red convertible the girls drove on a Napa Valley vacation or the engraved corkscrews they gave to each other-to signify what she and her friends seek when planning their next adventure. Similarly, BZB reveals in this post a deep emotional connection to Hawaii, specifically surfing there, though he articulates his feelings with a mix of identity statements, symbols, and stories:

i go to hawaii to surf period. to get the adrenaline rush and to grab the serotonin high....

i'm a californian. born and bred to surf, but the real waves are island swells..... i work all year saving for a 'surf safari'. i practice nearly everyday in anticipation. i live it in my brain when my boss is giving me shit. it's my something to believe in. church in salt water. try it.

BZB's emotions are couched in imagery. His "surf safari” is the prize for working hard all year; it is his spiritual quest. Consistent with the premise that metaphors and imagery serve as markers for hidden meanings (Zaltman, 1997), our data reveal that recalled decision emotions are often expressed not as emotion states, but instead as sunsets, white cap peaks, and island swells.

In contrast, emotional expression was more overt in the naturally occurring online data. Here, we found emotion words as well as symbols. Postings like Trent's on the Hawaii forum are common: "I waz thrilled by the images Zen posted from his vacation. I could see myself there. My heart pounding, I opened a new browser immediately to book a trip. In fact, I'm on Orbitz right now!" Trent admits that Zen's vacation images thrilled and inspired him to make vacation plans right away. Similarly, Dreamer435 on the forum dedicated to South Africa declared:

I happen across this thread about the Krueger safaris and this feeling comes over, not gentle and warm, but urgently slamming into me, 'I gotta go to Africa.'... Reading the postings and seeing the pictures ... I'm all about that. I text messaged my boyfriend at work and we started to talk about the trip. We're going in August!!!!

Dreamer435's narrative underscores the powerful influence of her emotional reactions on her 
decision behavior. Likewise, Endoo openly conveys that he booked his accommodations based on emotion, but now he is hoping to confirm that this was also a rational, even optimal choice:

We tried to be reasonable when we planned the trip, but The Reefs spoke to us. We booked on adrenaline... on urgency...on sheer fantasy-seeking. So, I guess I'm asking for someone to tell us it wasn't a mistake. Someone to say that it is exactly as amazing at it appears and that the nonscientific way of booking also turns out to be sound.

Vacation-task coders found decision emotions in $89 \%$ of the cases. In $90 \%$ of these cases, imagery preceded emotions, the ordering reflected by the Experiential-Decision Model. One participant contemplating an Atlantic City vacation notes, "The brochures ... definitely make me feel excited and ready to party.” Another participant writes, “This [Disney] video made me feel like a kid again.” In some cases, participants monitored their emotions for decision information. For example, reading a brochure of Australia, a participant notes, "Combined, the pictures were exciting and encouraged further consideration of Australia as a possible location.” Another participant states, "The description of the Bahamas affected me... I could feel the sun tingling my skin while I was at a fun party on the beach. I feel the Bahamas will be a lot of fun.”

Across three diverse data sets, we witness salient, vivid, and often strong emotions during experiential decision making. We label these more consciously-experienced emotions fantasy feelings to capture the idea that they are sought-after for their pleasurable qualities, are stoked by imagination, and are laced with information foretelling the hedonic and symbolic benefits of consumption. Appraisal of this affective information can have a direct affect on preferences and choice (Pham, 2004), as depicted in the Experiential-Decision Model.

The data also reveal subtle shades of emotion akin to an instinct or gut feeling that are less consciously perceived and that engender direct or indirect effects on decision behavior. We label these emotions facilitative feelings to describe the idea that they motivate approach/avoidance behavior by signaling consequences for one's well being. That is, when a choice option (e.g., a Caribbean cruise) is imagined, this imagery triggers a sense (e.g., this feels right) that this experiential product may satisfy self-relevant needs and goals. Guided by these feelings, "thought mobilization" may occur (Pham, 2004) as the decision process shifts to become more deliberate and analytical.

Facilitative feelings were less evident than fantasy feelings, consistent with the premise that such feelings are less salient and also less likely to be vividly recalled. For example, Kim, a student, said her choice of a family Caribbean vacation was based on "kind of a feeling" combined with "practical considerations," similar to her choice of colleges: "It's what it feels like. It's just kind of something you get from looking. I don't know why.” Meg, a college senior, imagines a vacation in Costa Rica, stating, "I just felt myself [she snaps], like settle in.” When asked to explain, she says: "Totally at ease and content.” Bob, an avid traveler has a list of locations he would "love" to visit out of a "genuine desire" or because he is "enamored" with the culture: "You hear about places or experiences that just resonate with you." Yet, Bob is patient in pursuing his travel dreams: "I'm a savvy enough shopper to know that there are deals to be found if you look for them.” The tension between feelings and finances was especially hard for Tonya, a self-labeled "control freak," in her planning for a honeymoon. Facilitative feelings guided the selection of a cruise: "As soon as I got excited about it, we made the move; it was not going to happen unless I was excited." Tonya had her "heart set on Celebrity [a premium cruise line], but cost came into play,” which required her to “...make decisions that might hurt my own feelings.” She explains emphatically, "Because it means that I can’t have everything that I wanted, and that hurts my feelings. I had to be realistic, but when you're dealing with fantasy and reality...."

Staci provides a view of facilitative feelings at the "How Does It Feel" stage in experiential decisions, explaining that something like a vacation is chosen because it "felt like 
you, or felt like something you want it to be, without nickel and diming it mentally." She describes the emotion driving such decisions as an "instinct," a "mentally comfortable" feeling, a "vibe," or a sense that "I belong in this setting" because it "feels right." When probed to describe when something feels right, she elaborates:

It matches my image of myself. I can see myself in this car, in this house, wearing this dress... My neighbor just got a Saab. She let me drive it. Fabulous car. Would never buy it for myself. As much as I liked it, it didn't feel right. Same when I was house hunting. I would walk in, and usually I knew within 60 seconds if the house was going to be one I was interested in. If I sat down and did an analysis I probably would have bought one that didn't have water in the basement. But, the emotional stuff overrode that very quickly.... ${ }^{3}$ This type of emotional response parallels the first and second-phase affective reactions described by Cohen and Areni (1991) in their dynamic model of affective response. That is, the positive emotion elicited during the decision is a response to meaning at the concept or idea level, not necessarily as a result of a conscious, elaborated interpretation of more concrete product features.

An interesting question is whether facilitative feelings represent reliable information about the self-experience fit of a product, as suggested by Staci's grounded view (see also Pham et al., 2001), or a biasing influence akin to an arousal-induced attitudinal halo effect that intensifies positive beliefs about a behavior and represses negative beliefs (Bagozzi, 1996). For some consumers, positive facilitative feelings may distort systematic information processing, as when a consumer who is excited by vacation images discounts cost as a decision factor in order to rationalize preference. For example, when "the seed [was] planted" for her family's riverrafting trip, Lea recalled feeling "real quick adrenaline, well this is exciting," though the rest of the planning, "the business end,” was “taken care of more quietly.” She remarks:

I know a lot of people probably say, 'OK, I have X and this is what I can spend on a trip.

We've never ever looked at any of our vacations in terms of financial; it's more about the experience and making sure that the kids have that experience, and we'll figure out how to pay for it later. It always has been.

Lea's claim to idiosyncrasy reveals that vacations are sacred for her, and that the co-mingling of money makes them profane (Belk, Wallendorf, \& Sherry, 1989). Her overgeneralization, "We've never ever looked at any of our vacations in terms of financial...," underscores this. In the final evaluation, she minimizes cost to reduce dissonance, and other factors that facilitate goals of creating memories and togetherness become important. Given Lea's planning excitement and post-trip pleasure, one might conclude that the effect of facilitative feelings amplified rather than distorted, the fit between self-relevant goals and the experience under consideration.

Individual Differences in Emotional Experience. Not all consumers are attuned to their emotions. One in six participants performed a fact-based attribute analysis first when planning, typically after stating vacations goals, whereas one in five expressed feelings first. The majority, two out of three participants, used imagery first. Half the participants evaluated what their feelings said about their preferences or about which products deserved further scrutiny for fit with the experiential self and consumption goals. In general, differences exist in how consumers identify, monitor, and use emotions when making judgments (Gohm \& Clore, 2000).

To explore these differences, at the close of their interviews we asked informants whether they thought their decisions were influenced by emotions. Maria stated that her choice of a ski

\footnotetext{
${ }^{3}$ Peterson et al. $(1986,142)$ argued that “Any good real estate agent knows home sales typically do not result from finding homes that match buyers' copious descriptions of the attribute-value content of their preference structure. Rather, sales are produced by showing home buyers a home they 'just love' and then getting them to purchase before they have the opportunity to calmly and rationally review the decision.”
} 
vacation in Jackson Hole, WY, was influenced “100\%, I guess," by emotions: "For me, Jackson Hole is sort of like a badge, a ski badge.... I've been to all these places. I can now say I've been to Jackson Hole.” In contrast, her husband Tim states that his decision making, "tends to be more factual." He estimates that emotions are only "30 to 40\%” of what influenced his plans in contrast to "real statistics," like how many runs are on the mountain or how many restaurants are nearby. He notes: "Those hard facts were more important to me than thinking about how pretty the mountains were." Though Maria affords more of a role to emotions, she used symbolism, "a ski badge,” instead of an emotion term such as pride. She also relates her feelings to progress toward her goal of adding another ski mountain to her list of conquered sites. Tim perceives his thinking as unemotional, though he admits to some emotion, which he equates with imagery.

In contrast, Mia recounts the fun that she and Susan have planning their vacations and bouncing ideas off each other: "I pay attention, to, if New Zealand is making me more excited, sparkly, enthusiastic, then I'm going to find the Website that's going to convince Susan that that's the right place to go!" When asked to elaborate on her decision emotions, Mia responds:

To what extent is it not emotional? Maybe the feasibility question? ... A vacation is about

creating something happy. It's entirely about what's going to make me happy. It's a gift to yourself, and that, to me, is $100 \%$ emotional. Does that make sense?

Similarly, Erin, a newly minted Ph.D., believes that her emotions "intellectualize" her decisions. A "traveler" who has backpacked extensively, she was conflicted over a vacation she took at a resort. Erin says that she is always aware of what she is thinking, but not of what she is feeling: I woke up one morning and [said]: I've got to mark the end of my Ph.D. I deserve this! I'm going to go to the beach. I've got to get out of here, see my best friend, go someplace hot. That was very emotionally based. The other emotions I was reckoning with were: You don't really like going on package holidays. It totally flies in the face of everything you claim to be and everything you want to cultivate in your life. So, I had those two sets of emotions going on, and I suppressed one in order to move forward with another. Despite Erin's claim that she is not always aware of what she is feeling, she is certain that rewarding herself with a beach vacation was emotionally driven. Facing tension between conflicting selves, she wrestled with her emotions and followed the path that felt most right.

\section{“Doing the Research": How Does It Fit?}

When informants were asked to describe "how the vacation-decision process unfolded," they tended to describe an analytical process. For example, Jack states: "We saw great air rates, the timing fit with our plans, we got a tip on Scottsdale from a travel agent, got travel books from the bookstore, and that was it.” Tim, who arranges his own business travel, likewise described a process that involved "doing the research" and just "assembling the information” about lodging, activities, and prices. Lea also recounts a series of decisions for her family’s river-rafting trip, starting with reviewing information from a travel agent, then using a video to choose a tour that took young kids for rafting, and then making a list of national parks and activities they wanted to see and do. She describes a winnowing of decisions, from macro/holistic to micro/analytic.

Other data echoed this theme of puzzle solving. Koast2Koast posted this query to a travel forum: "My husband and I are going to Beaches [resort]. How much privacy do you have and can you request a specific room? We are looking forward to being in a natural and beautiful environment. How was the smell of the farm nearby? Was the beach crowded?" Here Koast2Koast seeks confirmation for a decision already made ("going to Beaches”). Several informants also stated that their vacations represented what they "always” wanted to do, which 
implies an extended decision horizon and hints of hidden desire. Taken together, the data and analysis suggest that the full plan was more than the part of the process which informants described as "the decision," and included the part that we identify as the "How does it fit?" stage. However, analysis of some product attributes was common. Consumers often apply the same types of rational decision strategies to vacation choices as they do for instrumental products, although most often they do this after using imagination and emotion to guide and inform the process.

\section{DISCUSSION}

Across the datasets and modalities, we see that consumers experience imagery and emotion within the experiential decision process. We highlight below the findings which support prior research:

- decision emotions signal the fit between self-relevant goals and experiential consumption;

- imagery and decision emotions motivate further information processing and choice behavior;

- consumers seek information consistent with initial affective responses to choice stimuli; and

- decision emotions are often perceived as reliable and valid sources of information.

We also highlight findings that modify or extend prior research:

- experiential consumption is more than fun seeking; it is the pursuit of a true or possible self;

- experiential decisions elicit positive task-related affect; i.e., there is pleasure in the planning;

- experiential-decision emotions can be distinguished as fantasy or facilitative feelings; and

- recalled decision emotions are expressed as images and symbols more so than as emotion terms.

The fact that consumers seek pleasurable, subjective, psychosocial benefits through experiential consumption is theoretically important, in particular the finding that some consumers perceive others to be hedonistic fun-seekers, while they perceive themselves to seek experiences of substance. Consumers view the experiential self that emerges from self-identity themes as a true self or a possible self: the adventurer, the romantic, or the financially secure. The more self-relevant the experiential product, the more imagery is invoked, and the more significant the role of emotion is in the decision. As our informant Staci explains: "Emotions are what make a product valuable to you, how it fits our mental self-image. I can't see these decisions being strictly analytical. If that were the case, we'd all choose a very narrow band of things, because their features would line up completely.” Decision emotion is determined at least in part by what the product means for the consumer's self identity and how this makes the consumer feel.

Planning for experiential consumption is an experience itself, and positive emotions such as anticipation and excitement are a part of this process. Some consumers enjoy vicarious vacationing and experience not only positive emotions in response to product stimuli, but also positive task-related affect: pleasure in the planning, an emotional dimension of the decision process that is unexplored in the literature. Our research supports theories of emotion which posit that emotions are not irrational, but instead provide information and motivation (Bagozzi et al., 1998; Pham, 2004); how one feels about a plan signals how this experience fits pervasive selfthemes and enables realization of the experiential self.

We identify two forms of decision emotion. Fantasy feelings (akin to Campbell's (1987) “autonomous imaginative hedonism”) are sought-after imaginings-replays, remixes, prequels, and sequels - that provided a mental vacation before the physical one. We propose that fantasy feelings directly influence preferences for experiential choices. Facilitative feelings (akin to 
Pham's (2004) affective feelings) are "vibes” that "resonate,” just "feel right,” or "comforting," and are fleeting and fade into the background after mobilizing thoughts and directing information processing (Damasio, 1994; Pham, 2004). We propose that facilitative feelings have a direct or indirect influence on preferences. Evidence for the phenomenological distinction between fantasy and facilitative feelings reveals a potentially fruitful and interesting area for future research. In addition, the trove of emotional indicators found in our data underscores the need for research on how consumers make sense of and express their feelings during decision making.

Some consumers view vacations as sacred and de-emphasize cost in the decision. Other consumers wrestle with the tension between feelings and finances. This finding suggests that positive emotion may create a halo effect that dominates negative beliefs; or, it may be difficult to integrate emotional and analytical (belief-based) data in experiential decisions because the information conveyed by such factors is different. On the other hand, the self-relevance of experiential products, and, hence, the nature and influence of feelings evoked during choice may differ between consumers. Research must be conducted on different segments of consumers and in different decision contexts to explore these questions.

The Experiential-Decision Model is theoretically consistent with the few models that account for affect as an input to decision making, such as Cohen and Areni's (1991) Dynamic Model of Affective Response (DMAR), Holbrook's (1986) Consciousness-Emotion-Value (C-E-V) model, and the implicit models that guide the experimental research of Pham (1998), Shiv \& Huber (2000), and Yeung \& Wyer (2004). Research that expands the decision context to other hedonic or self-relevant consumption would provide generalized support for our emergent ideas about the nature of positive decision emotions. The Experiential-Decision Model may represent a general model of consumer choice that reduces to straight-forward attribute analysis when self-relevance, imagery, and emotion are minimally present in the decision. Research that explores the phenomenology of mundane, instrumental decisions may provide insight into the emotional boundaries of consumers' decision experiences.

The data-driven findings we present can inform marketing practice by suggesting means for enhancing emotion-driven marketing. By developing products and promotions that motivate consumers to imagine and project subjective meanings onto experiences, marketers facilitate the self-construction benefit of consumption. When vivid product images, e.g., a challenging rockclimbing wall or a hotel's pampering décor and amenities, provide self-relevant content for imaginative hedonism, this imagery serves as a catalyst for an emotional experience that is not only pleasurable, but that further influences decision behavior. In contrast, if imagery evokes more subtle sensations of anticipation, comfort, and similar facilitative feelings, this may guide and color subsequent information analysis. Every day, people make experiential decisions and experience emotions in the process. There is a reason why we feel warm and fuzzy or excited and aroused when considering an appealing consumption experience. This is because the experience matters; it presents consequences of importance to the self. And if it feels right, then it probably is.

\section{REFERENCES}

Ahuvia, A. C. (2005). Beyond the Extended Self: Loved Objects and Consumers’ Identity Narratives. Journal of Consumer Research, 32 (1), 171-84.

Arnould, E. J. \& Price L. L. (1993). River Magic: Extraordinary Experience and the Extended Service Encounter. Journal of Consumer Research, 20 (1), 24-45.

Averill, J. R. \& More, T. A. (1993). Happiness. In M. Lewis and J. M. Haviland (Eds.) Handbook of Emotions (pp. 617-629). New York: The Guilford Press. 
Bagozzi, R. P. (1996). The Role of Arousal in the Creation and Control of the Halo Effect in Attitude Models. Psychology \& Marketing, 13 (3), 235-264.

Bagozzi, R. P. \& Dholakia, U. M. (1999). Goal Setting and Goal Striving in Consumer Behavior. Journal of Marketing, 63 (Special Issue), 19-33.

Bagozzi, R. P., Baumgartner, H., \& Pieters, R. (1998). Goal-directed Emotions. Cognition and Emotion, 12 (1), 1-26.

Bagozzi, R. P., Gopinath M., \& Nyer P. U. (1999). The Role of Emotions in Marketing. Journal of the Academy of Marketing Science, 27 (2), 184-206.

Belk, R. W. (1988). Possessions and the Extended Self. Journal of Consumer Research, 15 (2), 139-68.

Belk, R. W., Ger G., \& Askegaard, S. (2003). The Fire of Desire: A Multisited Inquiry into Consumer Passion. Journal of Consumer Research, 30 (3), 326-51.

Belk, R. W., Wallendorf, M. \& Sherry, Jr, J. F. (1989). The Sacred and the Profane in Consumer Behavior: Theodicy on the Odyssey. Journal of Consumer Research, 16 (1), 1-38.

Bettman, J. R., Johnson, E. J., \& Payne, J. W. (1991). Consumer Decision Making. In Robertson, T. S., \& Kassarjian, H. H. (Eds.), Handbook of Consumer Behavior (pp. 50-84). Englewood Cliffs, NJ: Prentice Hall.

Campbell, C. (1987). The Romantic Ethic and the Spirit of Modern Consumerism. London: Blackwell.

Carver, C. S \& Scheier, M. F. (1990), Origins and Functions of Positive and Negative Affect-a Control-Process View. Psychological Review, 91 (1), 19-35.

Celsi, R. L., Rose, R. L., \& Leigh, T. W. (1993). An Exploration of High-Risk Leisure Consumption Through Skydiving. Journal of Consumer Research, 20 (1), 1-23.

Cohen, J. B. \& Areni, C. S. (1991). Affect and Consumer Behavior. In Robertson, T. S., \& Kassarjian, H. H. (Eds.), Handbook of Consumer Behavior (pp. 188-240). Englewood Cliffs, NJ: Prentice Hall.

Derbaix, C., \& Pham, M. T. (1991). Affective Reactions to Consumption Situations: A Pilot Investigation. Journal of Economic Psychology, 12 (2), 325-55.

Dhar, R., \& Wertenbroch K. (2000). Consumer Choice Between Hedonic and Utilitarian Goods. Journal of Marketing Research, 37 (1), 60-71.

Garg, N., Inman, J. J., \& Mittal, V. (2005). Incidental and Task-Related Affect: A Reinquiry and Extension of the Influence of Affect on Choice. Journal of Consumer Research, 32 (1), 154-159.

Gohm, C. L., \& Clore, G. L. (2000). Individual Differences in Emotional Experience. Personality and Social Psychology Bulletin, 26 (6), 679-97.

Hirschman, E. C., \& Holbrook, M. B. (1982). Hedonic Consumption: Emerging Concepts, Methods, and Propositions. Journal of Marketing, 46 (3), 92-101.

Holbrook, M. B. (1986). Emotions in the Consumption Experience: Toward a New Model of the Human Consumer. In Peterson, R. A., Hoyer, W. D., \& Wilson, W. R. (Eds.), The Role of Affect in Consumer Behavior (pp. 17-52). Lexington, MA: D.C. Heath.

Holbrook, M. B., \& Hirschman E. C. (1982). The Experiential Aspects of Consumption: Consumer Fantasies, Feelings, and Fun. Journal of Consumer Research, 9 (2), 132-40.

Isen, A. M. (1993). Positive Affect and Decision Making. In Lewis, M., \& Haviland J. M. (Eds.), Handbook of Emotions (pp. 261-78) New York: Guilford Press.

Lazarus, R. S. (1991). Progress on a Cognitive-Motivational-Relational Theory of Emotion. American Psychologist, 46 (8), 819-34.

Lincoln, Y. S. \& Guba, E.G. (1985). Naturalistic Inquiry. Beverly Hills, CA: Sage Publications.

Luce, M. F. (1998). Choosing to Avoid: Coping with Negatively Emotion-Laden Consumer 
Decisions. Journal of Consumer Research, 24 (4), 409-33.

Markus, H. \& Nurius, P. (1986). Possible Selves. American Psychologist, 41 (9), 954-969.

McCracken, G. (1998). The Long Interview. Newbury Park, CA: Sage Publications.

Mick, D. G., \& Buhl C. (1992). A Meaning-Based Model of Advertising Experiences. Journal of Consumer Research, 19 (3), 317-38.

Neelamegham, R., \& Jain, D. (1999). Consumer Choice Processes for Experience Goods: An Econometric Model and Analysis. Journal of Marketing Research, 36 (3), 373-86.

Otto, J. E., \& Ritchie, J. R. B. (1996). The Service Experience in Tourism. Tourism Management, 17 (3), 165-74.

Pearce, P. L. \& Lee U. I. (2005). Developing the Travel Career Approach to Tourist Motivation. Journal of Travel Research, 43 (3) 226-37.

Peterson, R. A., Hoyer W. D., \& Wilson W. R. 1986. The Role of Affect in Consumer Behavior: Emerging Theories and Applications. Lexington, MA: D.C. Heath.

Pham, M. T. (1998). Representativeness, Relevance, and the Use of Feelings in Decision Making. Journal of Consumer Research, 25 (2), 144-59.

Pham, M. T. (2004). The Logic of Feeling. Journal of Consumer Psychology, 14 (4), 360-69.

Pham, M. T., Cohen J. B., Pracejus, J. W., \& Hughes G. D. (2001). Affect Monitoring and the Primacy of Feelings in Judgment. Journal of Consumer Research, 28 (2), 167-88.

Price, L. L., Arnould E. J., \& Curasi, C. F. (2000). Older Consumers’ Disposition of Special Possessions. Journal of Consumer Research, 27 (2), 179-201.

Richins, M. L. (1997). Measuring Emotions in the Consumption Experience. Journal of Consumer Research, 24 (2), 127-46.

Schwarz, N., \& Clore G. L. (1996). Feelings and Phenomenal Experiences. In Higgins, E. T., \& Kruglanski, A. (Eds.), Social Psychology: A Handbook of Basic Principles (pp. 433-65). New York: Guilford.

Shiv, B., \& Fedorikhin A. (1999). Heart and Mind in Conflict: The Interplay of Affect and Cognition in Consumer Decision Making. Journal of Consumer Research 26 (3): 278-92.

Shiv, B., \& Joel H. (2000). The Impact of Anticipating Satisfaction on Consumer Choice. Journal of Consumer Research, 27 (2), 202-16.

Strauss, A. \& Corbin J. (1998). Basics of Qualitative Research: Techniques and Procedures for Developing Grounded Theory, $2^{\text {nd }}$ Edition. Thousand Oaks, CA: Sage.

Tsai, S. (2005). Utility, Cultural Symbolism and Emotion: A Comprehensive Model of Brand Purchase Value. International Journal of Research in Marketing, 22 (3), 277-291.

Van Boven, L. \& Gilovich T. (2003). To Have or To Do? That is the Question. Journal of Personality and Social Psychology, 85 (6), 1193-1202.

Yeung, C. W. M. \& Wyer, Jr., R. S. (2004). Affect, Appraisal, and Consumer Judgment. Journal of Consumer Research, 31 (2), 412-424.

Zajonc, R. B. (1980). Feeling and Thinking: Preferences Need No Inferences. American Psychologist, 35 (February), 151-75.

Zaltman, G. (1997). Rethinking Marketing Research: Putting People Back In. Journal of Marketing Research, 34 (4), 424-37. 


\section{FIGURE 1}

\section{EXPERIENTIAL-DECISION MODEL}
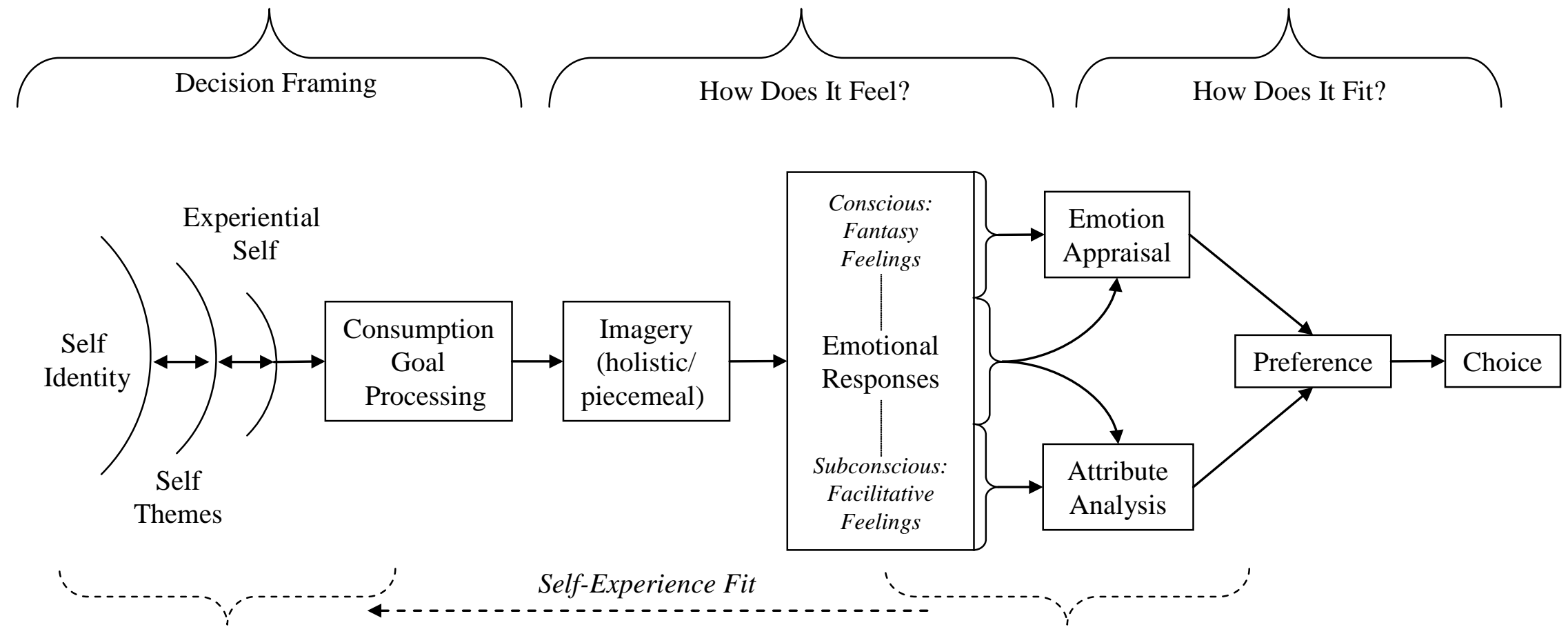


\section{TABLE 1}

\section{Vacation Task Decision-Element Frequencies and Process Sequence}

\begin{tabular}{|c|c|c|c|c|c|c|c|c|c|c|c|}
\hline \multirow[b]{2}{*}{ Decision Element $^{1}$} & \multicolumn{2}{|c|}{$\begin{array}{l}\text { Element } \\
\text { Present }\end{array}$} & \multicolumn{9}{|c|}{$\begin{array}{c}\text { Element Order in the Decision Process }{ }^{2} \\
\text { (Order Frequencies Across } 57 \text { Vacation Tasks) }\end{array}$} \\
\hline & Yes & No & $1^{\text {st }}$ & $2^{\text {nd }}$ & $3^{\text {rd }}$ & $4^{\text {th }}$ & $5^{\text {th }}$ & $6^{\text {th }}$ & $7^{\text {th }}$ & $8^{\text {th }}$ & Avg. \\
\hline Consumption Goals & 57 & 0 & 46 & 6 & 1 & 3 & 0 & 1 & 0 & 0 & 1.39 \\
\hline $\begin{array}{ll}\text { Imagery } & \\
& \text { (Holistic) } \\
& \text { (Piecemeal) } \\
& \text { Weighted } \\
\text { Avg. } & \end{array}$ & $\begin{array}{l}41 \\
50\end{array}$ & $\begin{array}{r}16 \\
7\end{array}$ & $\begin{array}{l}2 \\
2\end{array}$ & $\begin{array}{l}21 \\
14\end{array}$ & $\begin{array}{l}11 \\
14\end{array}$ & $\begin{array}{r}4 \\
10\end{array}$ & $\begin{array}{l}3 \\
5\end{array}$ & $\begin{array}{l}0 \\
3\end{array}$ & $\begin{array}{l}0 \\
2\end{array}$ & $\begin{array}{l}0 \\
0\end{array}$ & $\begin{array}{l}2.63 \\
\underline{3.38} \\
3.04\end{array}$ \\
\hline Emotional Response & 51 & 6 & 0 & 3 & 22 & 13 & 7 & 4 & 2 & 0 & 3.86 \\
\hline Emotion Appraisal & 28 & 29 & 1 & 0 & 4 & 6 & 7 & 7 & 2 & 1 & 4.86 \\
\hline Attribute Analysis & 54 & 3 & 0 & 7 & 2 & 18 & 12 & 8 & 6 & 1 & 4.63 \\
\hline Preference & 44 & 13 & 0 & 1 & 3 & 3 & 14 & 10 & 7 & 6 & 5.68 \\
\hline Choice & 56 & 1 & 6 & 6 & 1 & 0 & 4 & 18 & 12 & 9 & 5.45 \\
\hline
\end{tabular}

Notes: Consumption goals (e.g., memories, togetherness, value) were identified from a set of goals derived from the qualitative analysis; Imagery was coded as holistic (e.g., "big picture" symbols and fantasy) and/or piecemeal (e.g., specific images); Emotional responses were identified as emotion terms (e.g., happy, excited, thrilled) or metaphors; Emotion appraisals were identified as explicit evaluations of the informational value of emotional responses; Attribute analysis was identified as fact-based evaluations of product features; Preference was identified as statements of product-alternative evaluation, liking or inclination; Choice was identified as an explicit selection of a product alternative. ${ }^{2}$ Frequencies represent the number of times the coders identified each element in the decision process and the sequential position of each element. The average score (column 12) is a weighted average of the frequency and sequential position. 


\section{APPENDIX}

\section{INTERVIEW INFORMANTS}

\begin{tabular}{|c|c|c|c|}
\hline Pseudonym & Gender/Age & Family Status & Occupation/Education \\
\hline Alice & F/mid 40s & Married, 3 children & Administrative Assist./some college \\
\hline Ana & F/late 60s & Married, 3 children & Housewife and Mother/B.A. \\
\hline Bob & M/early 40s & Single & Administrator/M.P.S. \\
\hline Bryce & M/early 40s & Married, 2 children & Professor/Ph.D. \\
\hline Erin & F/early 30s & Single & Professor/Ph.D. \\
\hline Jack & M/late 30s & Married & Sales Manager/B.A. \\
\hline $\mathrm{Jim}$ & M/early 30s & Married & Administrative Assistant/B.A. \\
\hline Kay & F/early 40s & Married, 2 children & Youth Director/BA \\
\hline Kim & F/late teens & Single & College Student $/ 1^{\text {st }}$ year \\
\hline Lea & F/early 40s & Married, 3 children & Mother/B.A. \\
\hline Mark & M/late 30s & Single, 1 daughter & Market Researcher/BS \\
\hline Max & M/late 30s & Married, 1 son & Lawyer/B.S. and J.D. \\
\hline Meg & F/early 20s & Single & College Student $/ 4^{\text {th }}$ year \\
\hline Mia & F/late 30s & Married to SSP & Computer Support Specialist/B.A. \\
\hline Regan & F/early 30s & Married, 1 child & Elementary Education/M.S. \\
\hline Russ and & M/late 30s and & Married, 1 child & Design Engineer/M.S. and \\
\hline Lani & F/late 30s & & Product Manager/H.S. \\
\hline Staci & F/late 30s & Single & Lecturer/M.S. \\
\hline Tonya & F/mid 20s & Married & Career counselor/B.A. \\
\hline Tim and & M/early 30s and & Married & Sales Manager/M.B.A. and \\
\hline Maria & F/late 20s & & Advertising Manager/B.A. \\
\hline $\begin{array}{l}\text { Toby and } \\
\text { Sela }\end{array}$ & $\begin{array}{l}\text { M/early 30s and } \\
\text { F/mid 30s }\end{array}$ & Married, 1 child & $\begin{array}{l}\text { Security Supervisor/H.S. and } \\
\text { Hair Stylist/H.S. }\end{array}$ \\
\hline Will and & M/mid-30s and & Married, 1 child & Arborist, Business Owner/B.A. and \\
\hline Lina & F/mid-30s & & Physical Therapist/M.S. \\
\hline
\end{tabular}

Note: Informants whose comments are not quoted in the text are not described above. 